\title{
The effect of family-centered care on adherence to treatment in patients with type 2 diabetes
}

\author{
Masumeh Hemmati Maslakpak $^{1}$ (D), Shahin Alipour ${ }^{2}$ (D), \\ Nader Aghakhani $^{3}$ iD, Hamidreza Khalkhali ${ }^{4}$ \\ ${ }^{1}$ Corresponding author; Maternal and Childhood Obesity Research Center, Urmia University of Medical Sciences, Urmia, Iran \\ Tel: +9844132754961Ｅmail: hemmati_m@umsu.ac.ir \\ ${ }^{2}$ Student Research Committee, Urmia University of Medical Sciences, Uremia, Iran \\ ${ }^{3}$ Department of nursing, Urmia University of Medical Sciences, Uremia, Iran \\ ${ }^{4}$ Department of Biostatistics, Urmia University of Medical Sciences, Uremia, Iran
}

Citation Hemmati Maslakpak M, Alipour Sh, Aghakhani N, Khalkhali HR. [ The effect of family-centered
care on adherence to treatment in patients with type 2 diabetes]. J Birjand Univ Med Sci. 2020; 27(2): 161-
71. [Persian]

\begin{abstract}
Background and Aim: The family can play an important role in adapting patients with diabetes to lifestyle changes, so that the family, as the most essential pillar of society, is responsible for the proper care of the patient with diabetes; Therefore, the present study was conducted to determine the effect of family-centered care on the adherence to treatment of patients with type 2 diabetes.

Materials and Methods: In this quasi-experimental study, 80 patients with type 2 diabetes and one member of their family were selected by convenience sampling method and randomly assigned to two of intervention and control groups. Adherence to treatment was assessed using a researcher-made questionnaire and laboratory values before and 3 months after the intervention. Data were analyzed using the Kolmogorov-Smirnov, Independent t-test, paired t-test, and Chi-square test.

Results: After the implementation of the family-centered care program, increased mean scores for patient adherence to treatment in the intervention group compared to the control group, this increase was statistically significant $(\mathrm{p}=0.0001)$. The results showed a decrease in the mean score of fasting blood glucose, random blood glucose and glycosylated hemoglobin in the intervention group compared to the control group. This decrease was statistically significant $(\mathrm{P}=0.0001)$.

Conclusion: Family-centered care can increase adherence to treatment, and decrease fasting blood glucose, random blood glucose and hemoglobin glycosylated levels. Therefore, it is recommended that family pay more attention to diabetic members.
\end{abstract}

Key Words: Adherence to Treatment; Blood glucose; Family-Centered Nursing; Type 2 Diabetes Mellitus 


\section{تأثير مراقبت خازواده محور بر تبعيت از درمان در بيماران مبتلا به ديابت نوع دو}

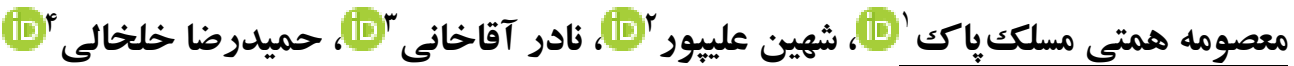

\section{جكيله}

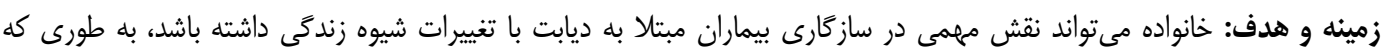

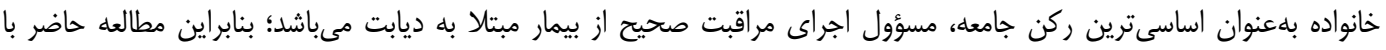

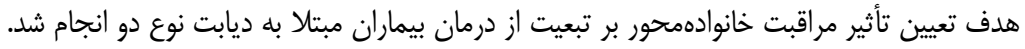

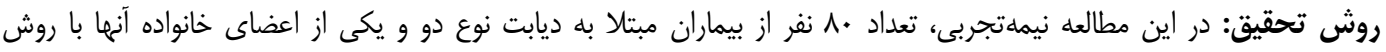

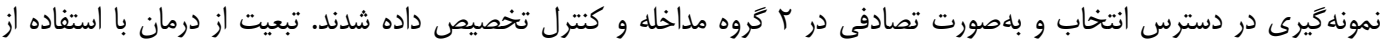

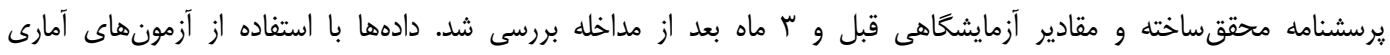

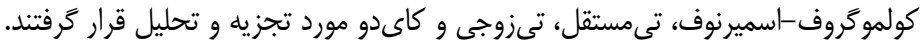

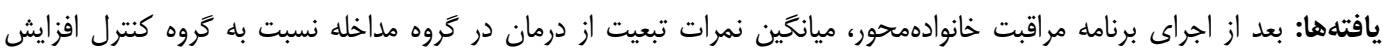

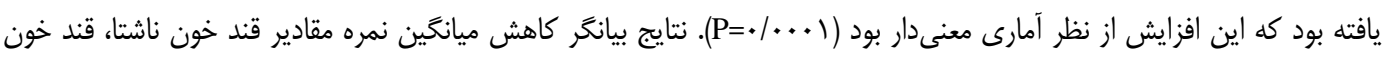

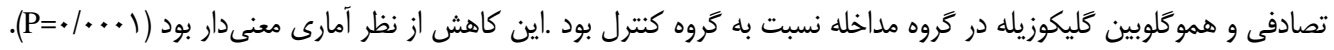

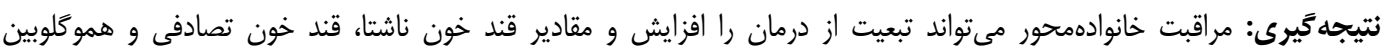

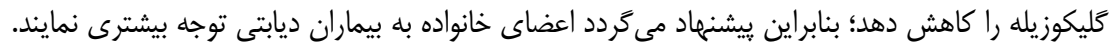
وازههاى كليدى: تبعيت از درمان؛ قندخون؛ يرستارى خانواده محور؛ ديابت نوع دو

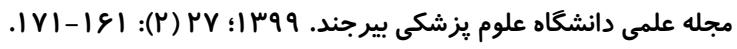
دريافت:

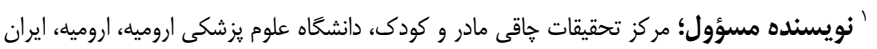

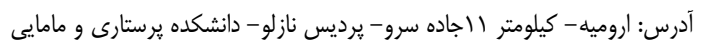

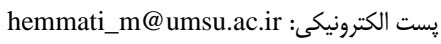
تلفن:

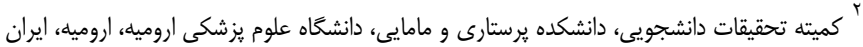

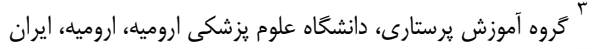

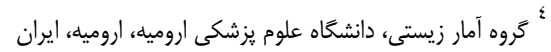


بالا در ارتباط است (1). ميزان مرگ و مير در بيمارانى كه به مقدمه

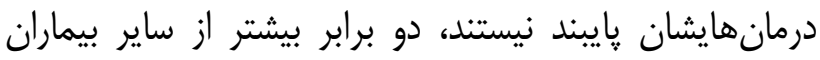

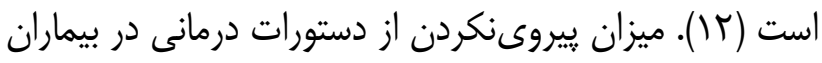

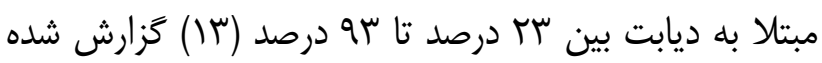

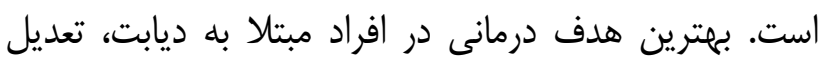

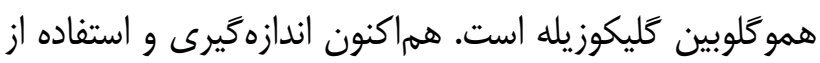

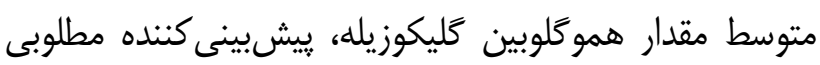

براى عوارض ديابت تلقى مى شود (If).

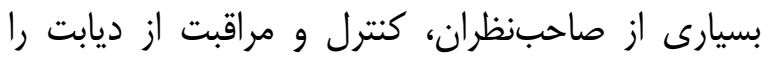

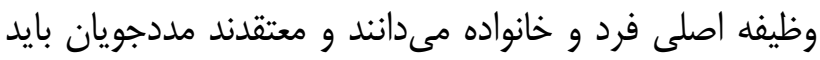

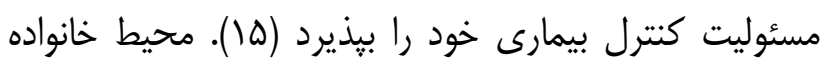

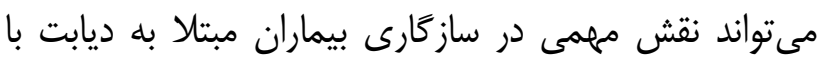

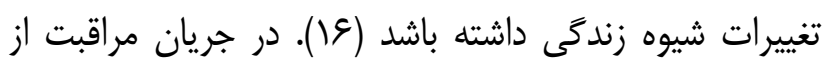

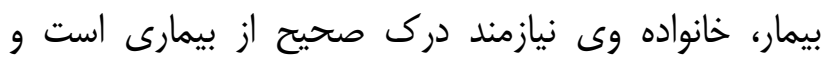

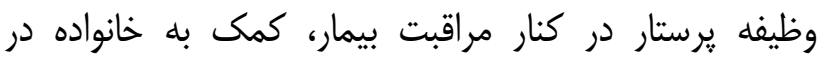

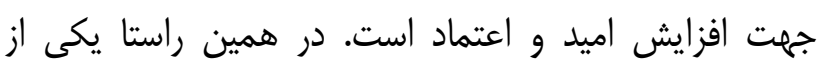

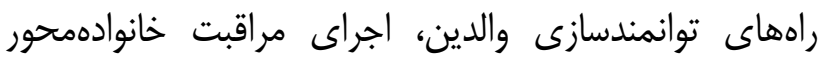

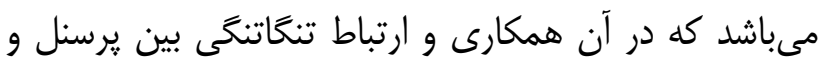

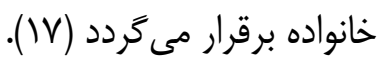

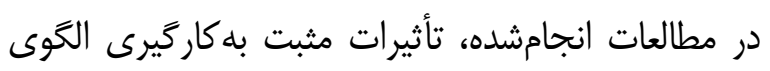

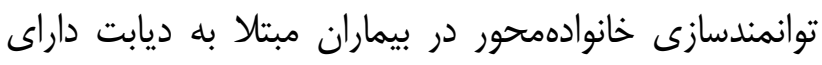

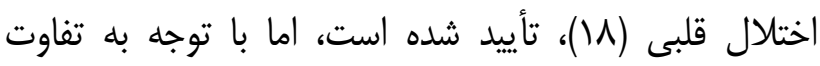

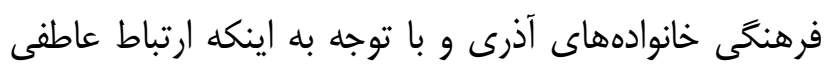

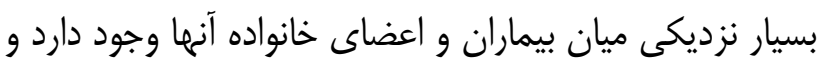

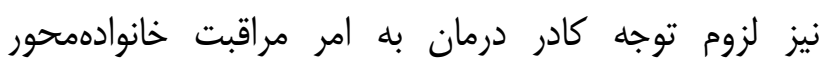

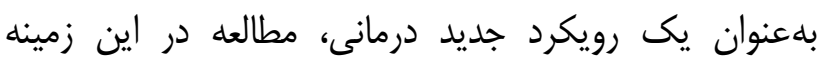

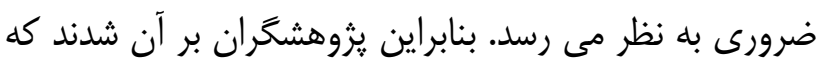

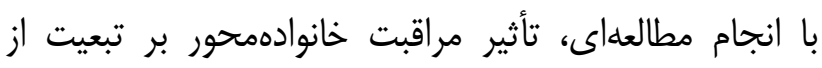
درمان در بيماران مبتلا به ديابت نوع دو را تعيين كنند.

روش تحقيق اين مطالعه نيمهتجربى، با مجوز كميته اخلاق دانشخاه

يكى از بزركترين جالشهايى كه در قرن بيست و يكما

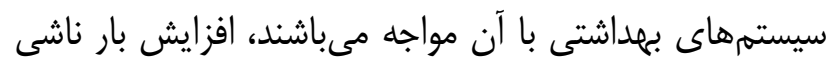

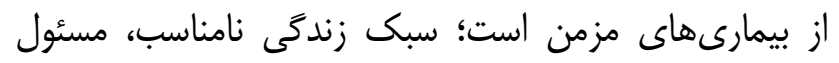

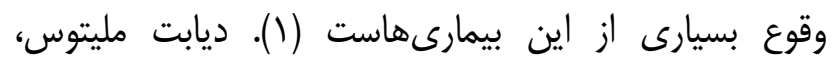

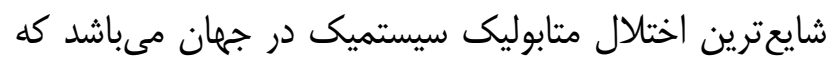

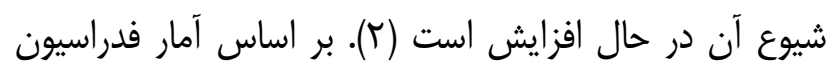

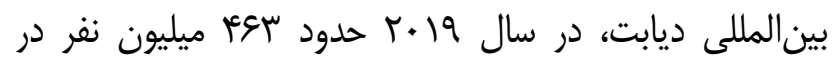

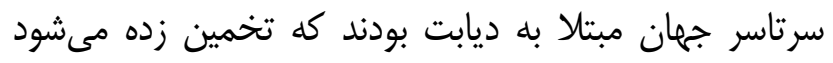

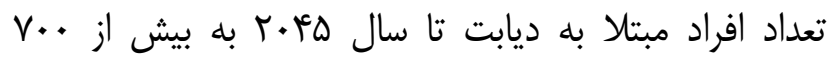

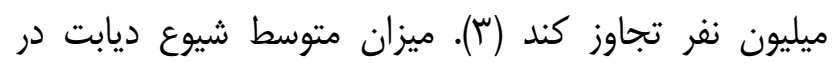

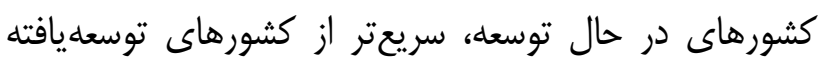

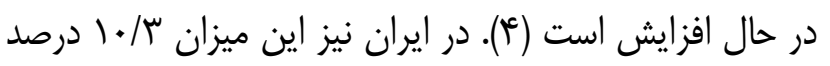

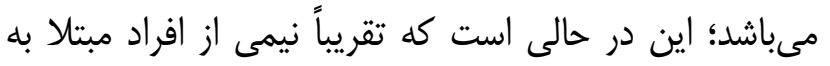
ديابت، از بيمارى خود مطلع نيستند (ه).

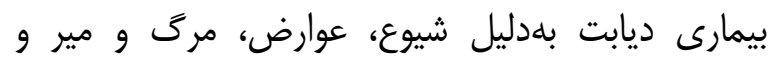

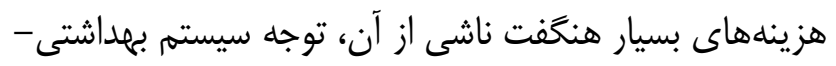

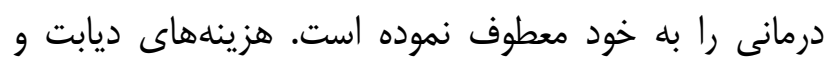
عوارض آن در مقايسه با ساير بيمارىها بسيار بالاست (ج). در دران

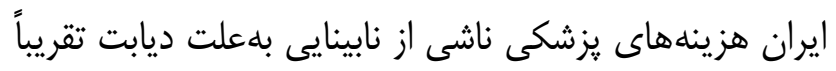

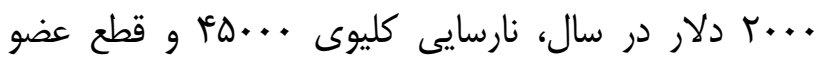

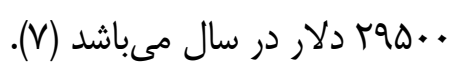
يكى از رفتارهاى مرتبط با بيمارى كه درمان موفقيتآميز

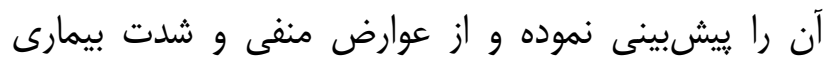

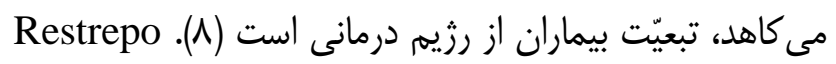

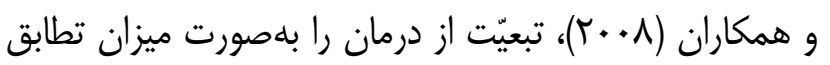

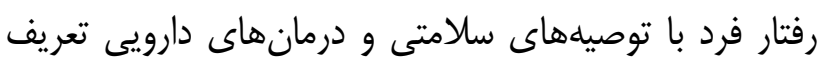

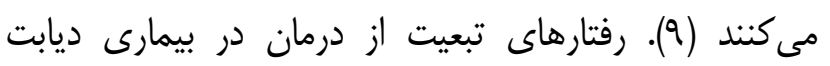

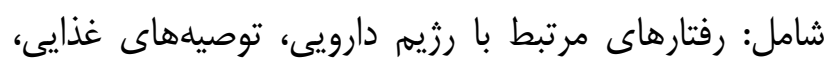

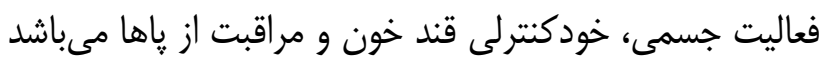

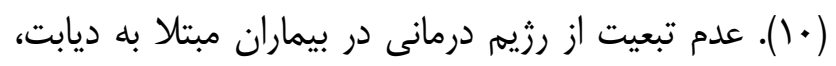
با بسترىشدنهاى مكرر در بيمارستان و هزينهانهاى درمانى درانى 


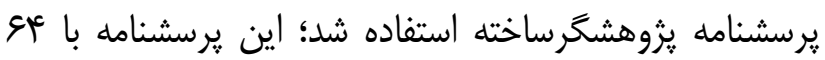

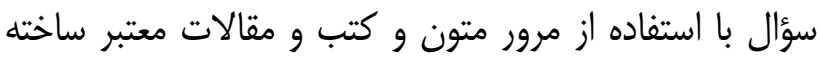

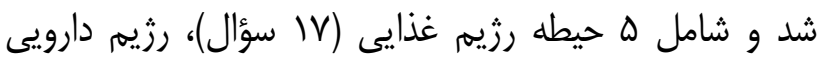

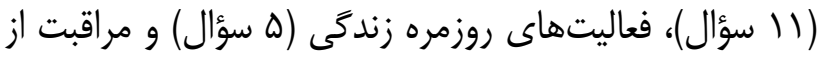

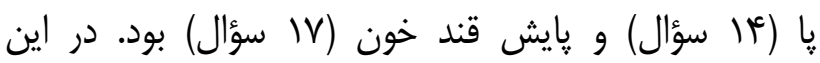

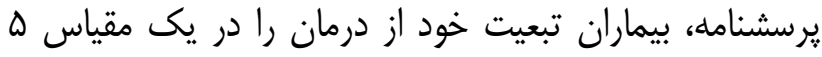

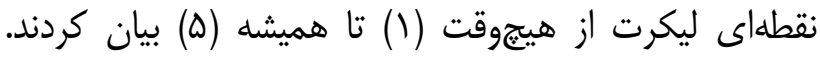

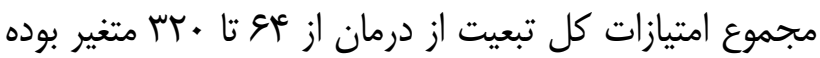

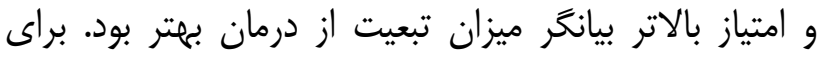

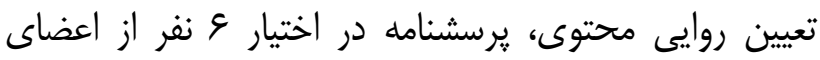

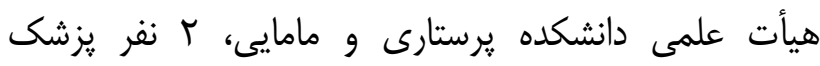

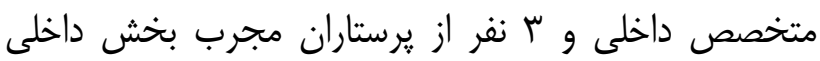
قرار داده شد و در نهايت با توجه نظرات و و اعمال نظرات

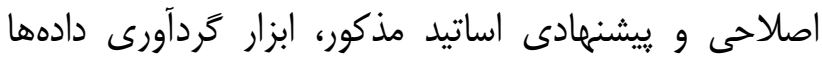
معتبر شد. شاخص روايى محتواى 'يرسشنامه تبعيت از درمان

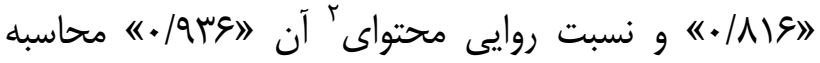

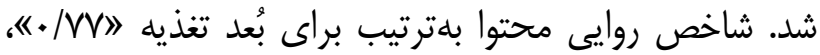

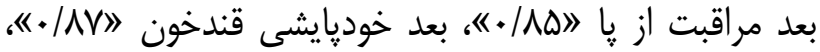

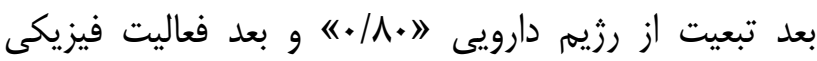

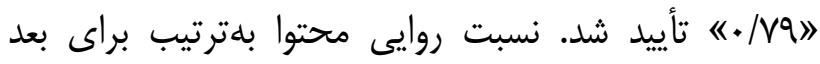

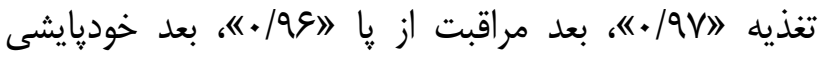

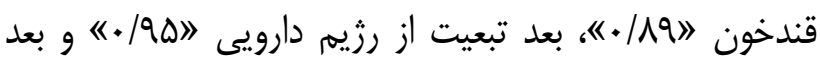

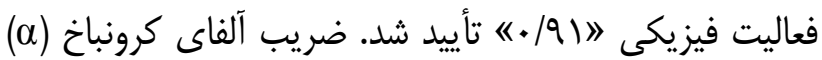

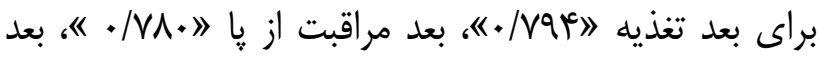

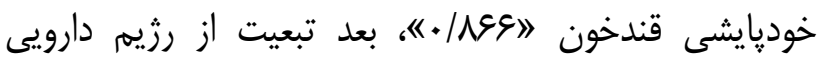
و و بعد فعاليت فيزيكى "/M9V》

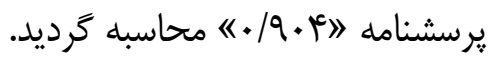
اندازهيرى قد (وضعيت ايستاده و بدون كفش) با استفاده

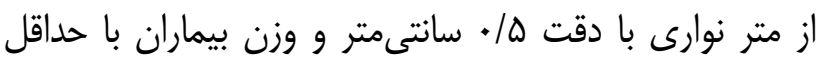

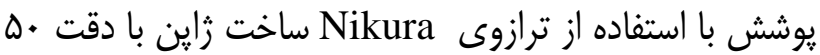

\footnotetext{
${ }^{1}$ Content validity index

${ }^{2}$ Content validity ratio
}

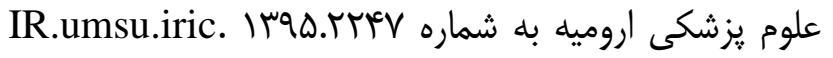
بdصورت قبل و بعد در سال هوسا - عوسا انجام شد. تعداد

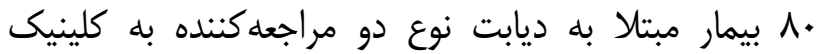

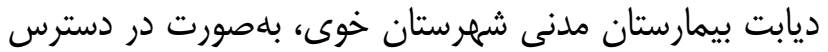

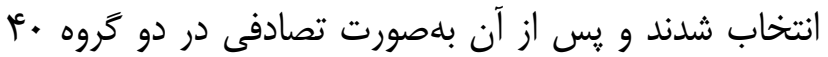
نفره كنترل و مداخله تخصيص داده شدند. حجم نمونه با با.

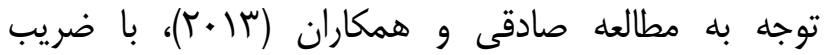

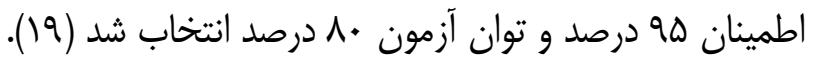

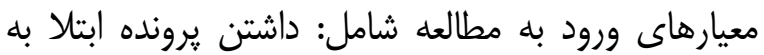

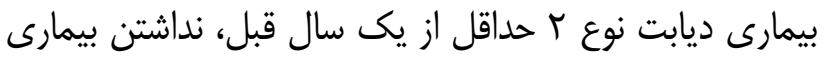

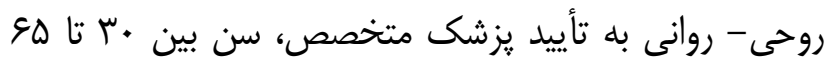

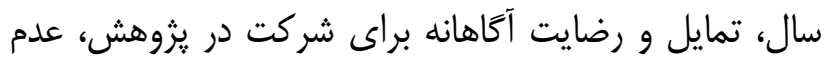

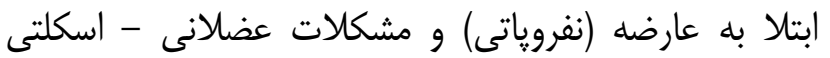

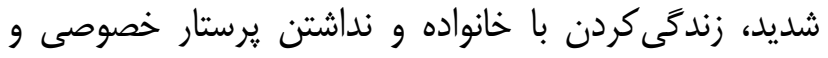

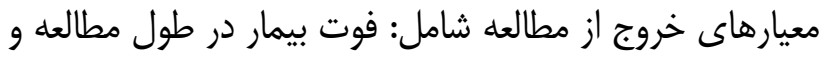

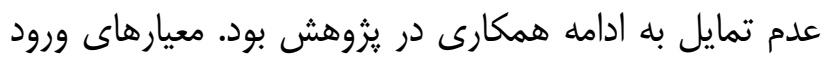

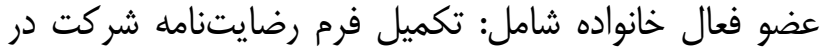

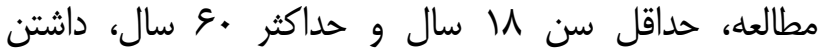
حداقل سواد براى خواندن و نوشتن، تمايل به شركت درل در

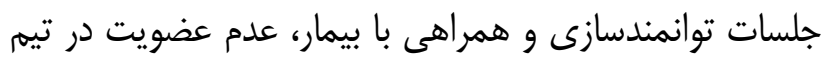
يزشكى، عدم شركت در كلاسها و دورههاى توانمندسازى

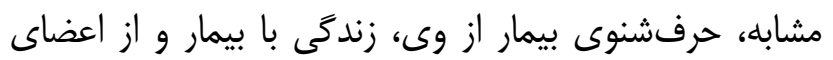

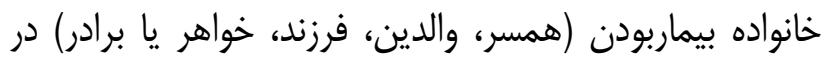

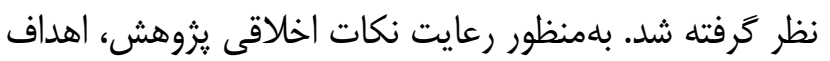

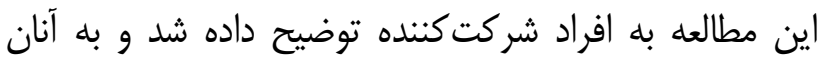
اين اطمينان خاطر داده شد كه اطلاعات آنها محرمانه باقى دانى

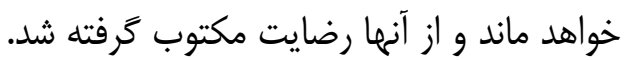

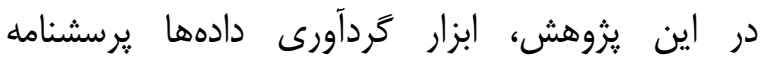

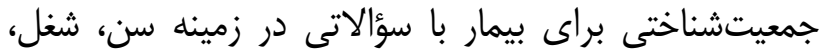

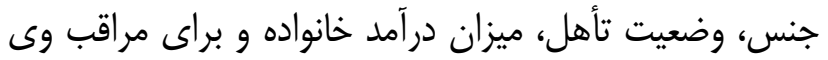
در خانواده با سؤالاتى در زمينه جنس، سن، مين، تحصيلات درات و

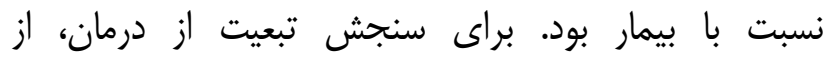


مراقبتهاى روتين درمانگاه را دريافت كردند. ابتدا نيازهاى

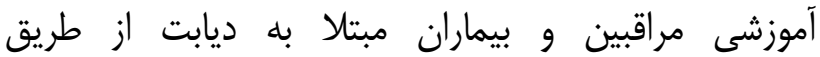

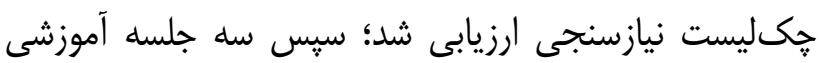
يك و نيم ساعته يس از هماهنگحى با افراد مورد مطالعه (بيمار

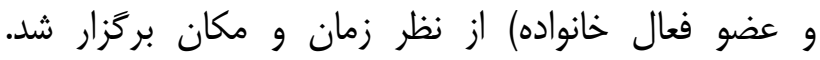

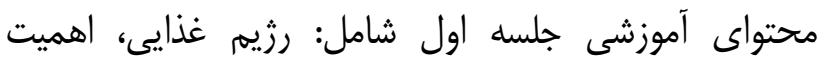

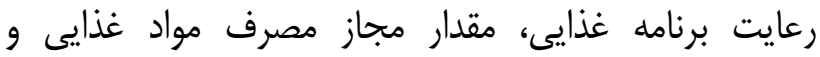

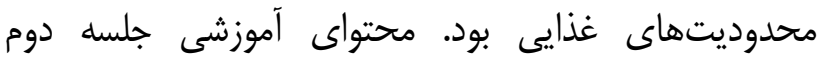

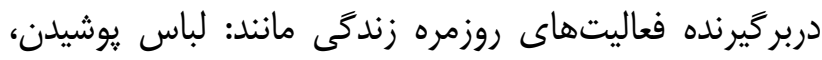

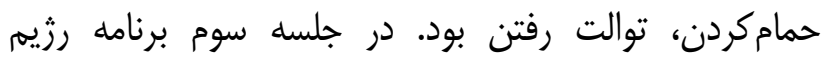
دارويى (نحوه مصرف داروها، عوارض جانبى آنها، علت تجويز توني

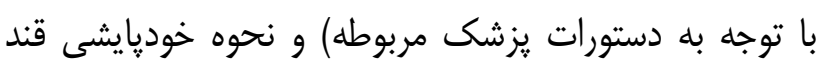
خون آموزش داده شد.

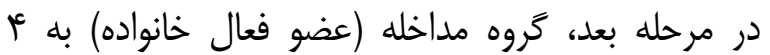

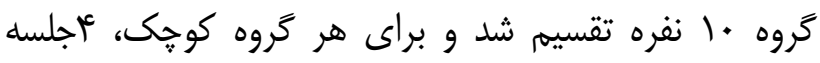

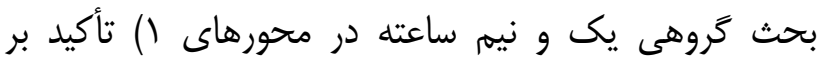

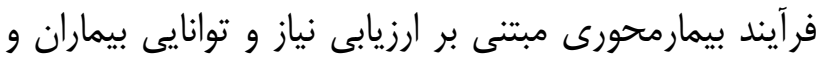

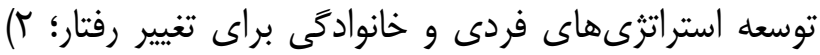

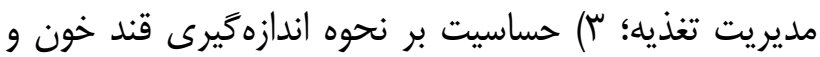

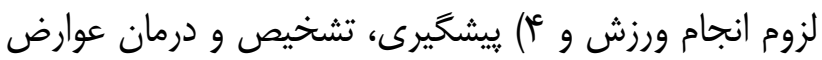

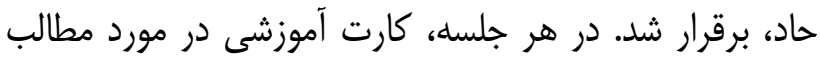

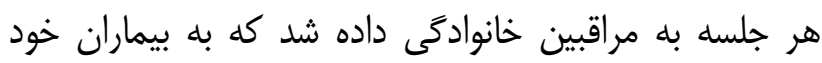

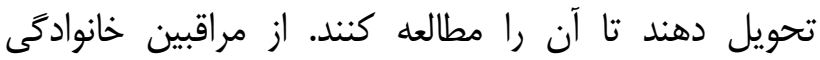

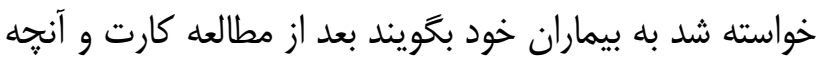

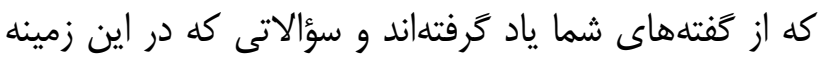
برايشان مطرح مىباشد را در يك بركه بنويسند (بهعنوان

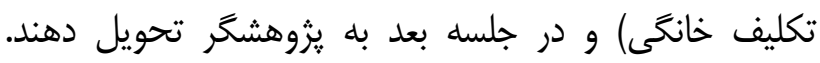

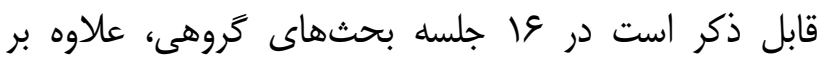

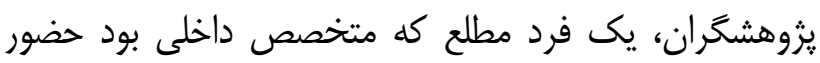

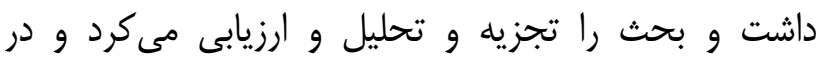

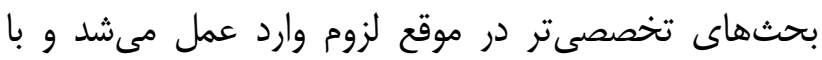

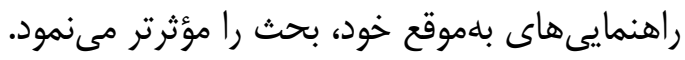

گرم انجام شد. شاخص توده بدنى، از تقسيه وزن بر حسب

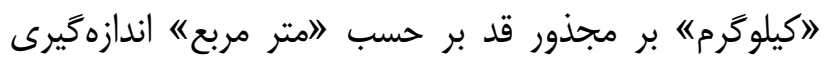

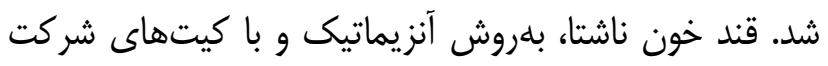

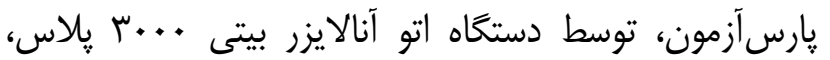

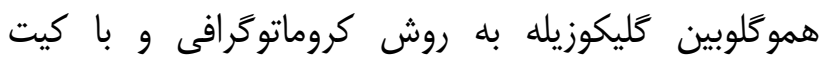
مخصوص توسط دستخاه الكتروليت آنالايزر

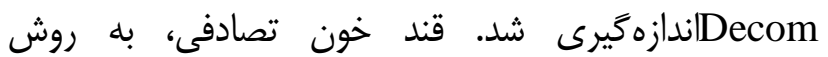
آنزيماتيك و با كيتهاى شركت پارسآزمون، توسط دستخاه

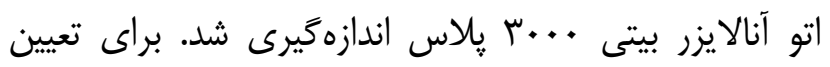

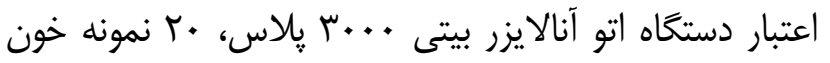

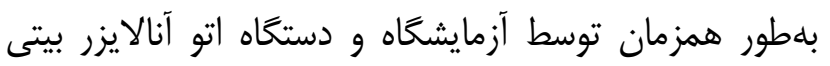

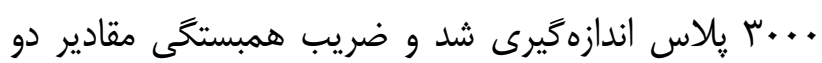

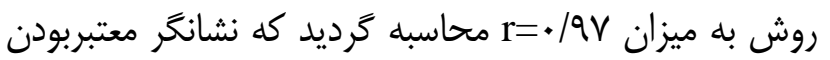

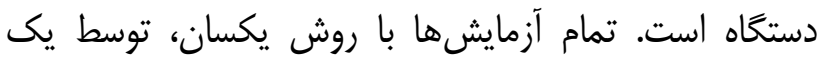

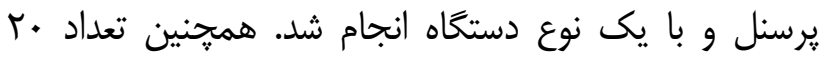

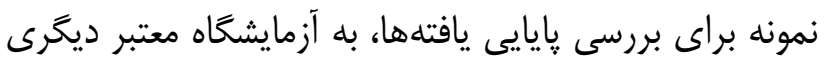

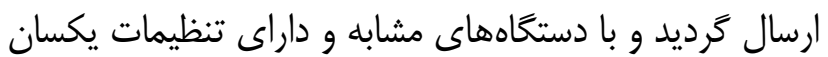

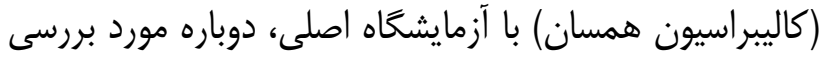

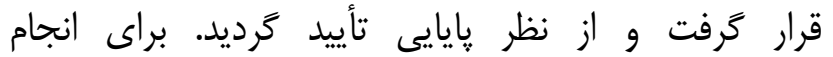

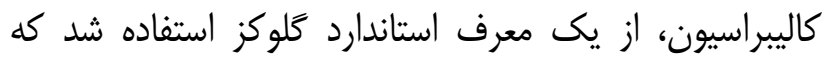

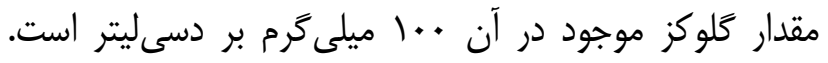

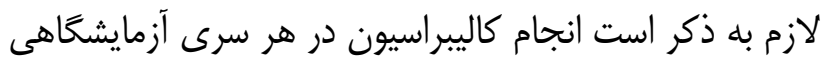
انجام گرديد تا از دقت و صحت عملكرد دستخاه إنمام الطمينان

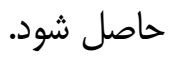
بعد از ييشآزمون، •^م بيمار بلروش تصادفى برحسب دو

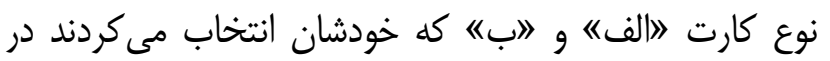

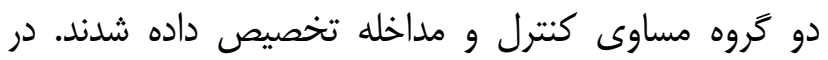

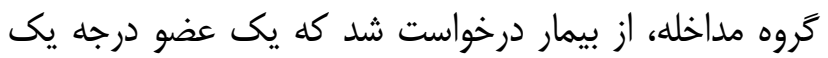

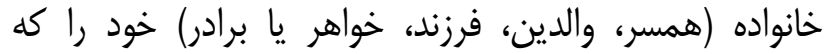
بيشترين تعامل و ارتباط را با وى را داشته، معرفى نمايد،

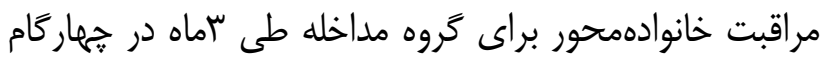
اصلى انجام شد. قابل ذكر است كه افراد كروه مروه كنترل 


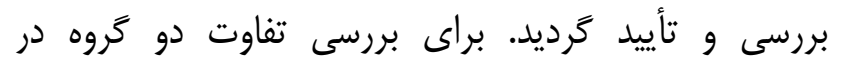

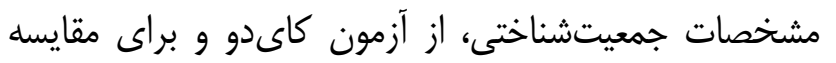

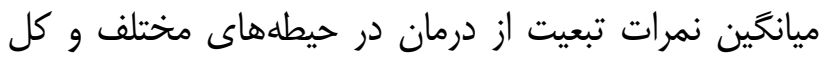

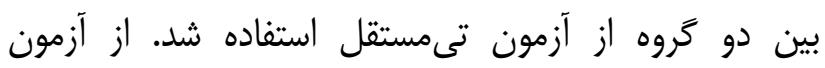
تىزوجى نيز براى مقايسه درون كروهى استفاده شد. تحليل

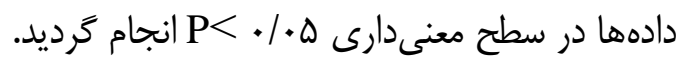

\section{يافته ها}

نتايج آزمون آمارى كاىدو نشان داد كه بيماران در دو

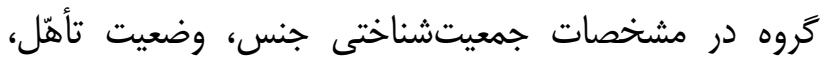

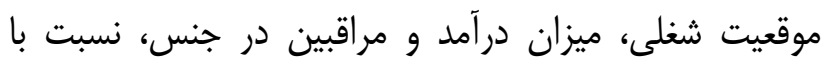

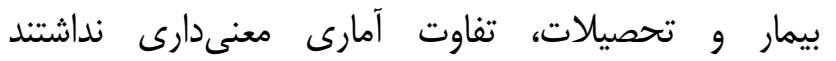

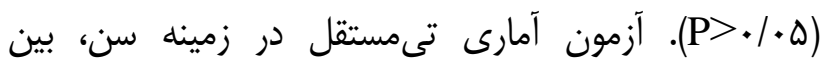

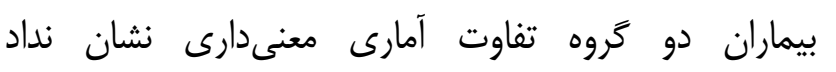

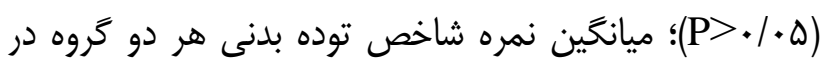

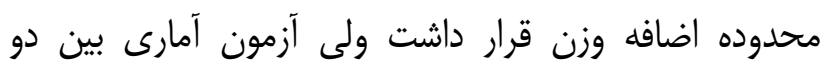

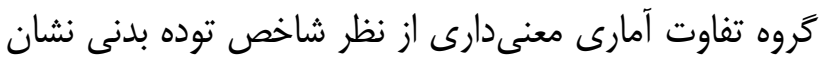

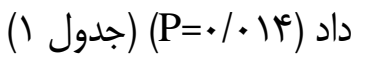

بعد از اتمام ارزشيابى فر آيند و بعد از اطمينان از توانمندى

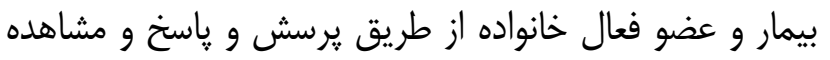

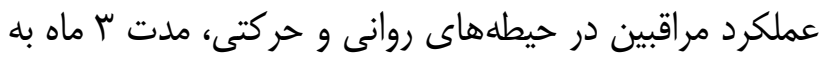

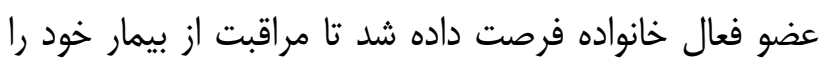

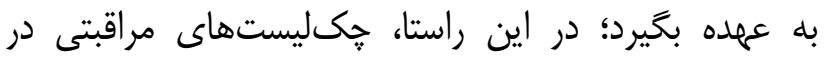

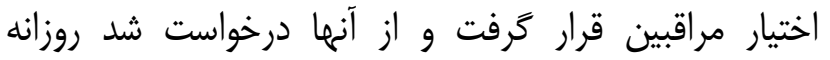

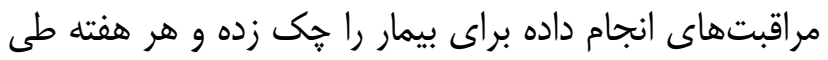

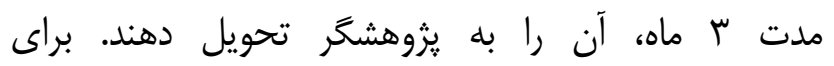

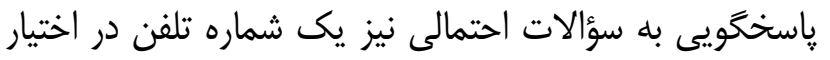

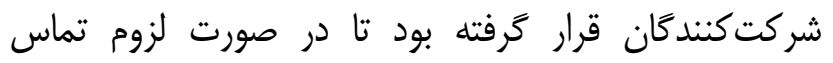

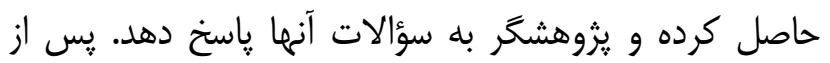

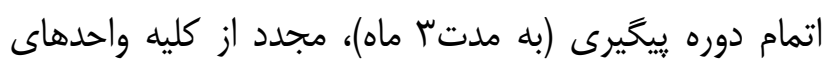

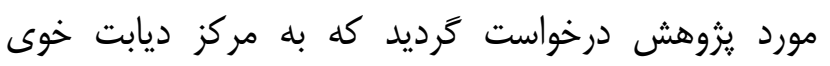

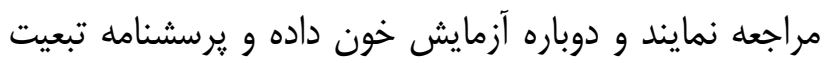

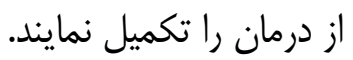

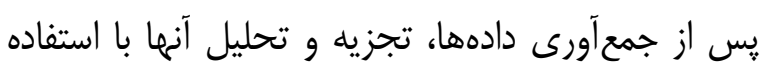

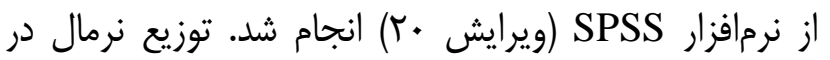

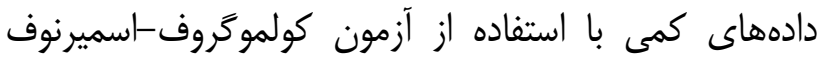
جدول ا - توزيع فراوانى مطلق و نسبى مشخصات دموتر افيك افراد مورد مطالعه

\begin{tabular}{|c|c|c|c|c|}
\hline \multirow{2}{*}{ آزمون آمارى معنى دارى } & $\begin{array}{c}\text { كنتر } \\
(N=f+)\end{array}$ & $\begin{array}{c}\text { مداخله } \\
(N=r+)\end{array}$ & \multirow{2}{*}{\multicolumn{2}{|c|}{ متغير ها }} \\
\hline & تعداد (درصد) & تعداد (درصد) & & \\
\hline \multirow{2}{*}{ אזוג/. } & $19(F \vee / D)$ & $1 N(F \Delta)$ & مرد & \multirow{2}{*}{ جنس } \\
\hline & $r(\Delta r / \Delta)$ & $r r(\Delta \Delta)$ & زن & \\
\hline \multirow{4}{*}{. $/$ DY } & $r(V / \Delta)$ & $1(\Gamma / \Delta)$ & مجرد & \multirow{4}{*}{ تأهّل } \\
\hline & $r N(V \cdot)$ & $M I(V V / \Delta)$ & متاهل & \\
\hline & $g(10)$ & $V(I V / \Delta)$ & بيوه & \\
\hline & $r(V / \Delta)$ & $I(T / \Delta)$ & مطلقه & \\
\hline \multirow{4}{*}{./NQT } & $r \cdot(\Delta \cdot)$ & $r \xi(\xi \Delta)$ & بيكار يا خانه دار & \multirow{4}{*}{ شغل } \\
\hline & $V(I V / \Delta)$ & $1(\Gamma / \Delta)$ & كارمند & \\
\hline & $\mid r(r \cdot)$ & $\mid r(r \cdot)$ & آزاد & \\
\hline & $I(\Gamma / Q)$ & $1(T / \Delta)$ & بازنشسته & \\
\hline \multirow{3}{*}{.$/ 1 r q$} & $q(\Gamma T / \Delta)$ & $1 \cdot(K \mu / \Lambda)$ & ناكافى & \multirow{3}{*}{ ميزان درآمد } \\
\hline & $r \cdot(\Delta \cdot)$ & $r \varphi(\Delta V / \tau)$ & تا حدودى كافى & \\
\hline & $\Pi(T V / \Delta)$ & $F(1 / / \Lambda)$ & كافى & \\
\hline
\end{tabular}




\begin{tabular}{|c|c|c|c|c|}
\hline \multicolumn{5}{|c|}{ ادامه جدول يكى } \\
\hline سطح معنى دارى & كنترل & مداخله & \multirow{3}{*}{\multicolumn{2}{|c|}{ متغير ها }} \\
\hline آزمون آمارى & $(N=f+)$ & $\left(N=r_{+}\right)$ & & \\
\hline كاى & تعداد (درصد) & تعداد (درصد) & & \\
\hline \multirow{2}{*}{$\cdot \mid r q 1$} & $r Y(g \cdot)$ & $r Y(\Delta \Delta)$ & مرد & \multirow{2}{*}{ جنس مراقب } \\
\hline & 19()$\left.^{4} \cdot\right)$ & $M\left(f^{c} \Delta\right)$ & 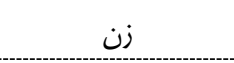 & \\
\hline \multirow{3}{*}{$\cdot /$ / q } & $\Delta(I Y / \Delta)$ & $q(Y T / Q)$ & همسر & \multirow{3}{*}{ 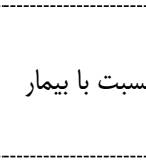 } \\
\hline & $M(V / D)$ & $r q(V r / \Delta)$ & 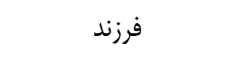 & \\
\hline & $r(1 \cdot)$ & $r(\Delta)$ & 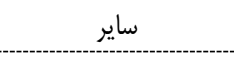 & \\
\hline \multirow{2}{*}{$\cdot 11 \cdot+$} & $川(T V / D)$ & $M(F \Delta)$ & دييله & تحصيلات \\
\hline & $19(V / / \Delta)$ & $r Y(\Delta \Delta)$ & تحصيلات دانشگاهى & مراقب \\
\hline آزمون تى معنى مستقل & انحراف معيار土ميانحَين & انحراف معيار土ميانگين & \multicolumn{2}{|l|}{ متغير } \\
\hline$\cdot / r q$ & 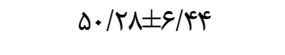 & $\Delta) / Q \wedge \pm \vee / \vee \varepsilon$ & \multirow{3}{*}{\multicolumn{2}{|c|}{ 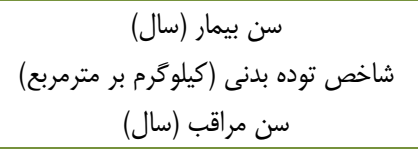 }} \\
\hline $.1 \cdot 14$ & $r q / \cdot r \pm r / v r$ & $r \varepsilon / q 1 \pm r / v q$ & & \\
\hline.$/ T H$. & $r \Delta / \kappa r \pm r / r q$ & $r V / r r \pm \Lambda / V T \Delta$ & & \\
\hline
\end{tabular}

جدول r- مقايسه ميانكَين نمرات همو كلوبين كليكوزيله قندخون ناشتا و تصادفى، درون و بين دو تروه كنترل و مداخله قبل و بعد از اجراى مراقبت خانواده محور

\begin{tabular}{|c|c|c|c|c|}
\hline سطح معنىدارى & تفاضا كنت ا - مداخله & ترووه كنترل & تَروه مداخله & \\
\hline 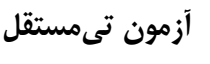 & سصل سرل- مداحله & انحر افمعيار土ميانخين & انحرافمعيار土ميانكين & 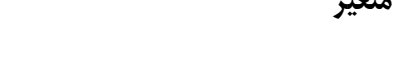 \\
\hline . Itet &.$- / 48$ & $q / \Delta I \pm T / r T \Delta$ & $q / \backslash \Delta \pm / / \Delta V V$ & هموكلوبين كَليكوزيله قبل از مداخله \\
\hline $.1 \cdots+1$ & $-1 / \wedge \Delta$ & $q / \cdot V \pm r / r q q$ & 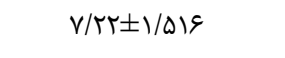 & هموكلوبين كَليكوزيله بعداز مداخله \\
\hline- & - & ./TVT & $.1 \cdot 1$ & سطح معنى دارى آزمون تىزوجى \\
\hline.$/ D Q F$ & $19 / 9$ & $r / q / \varsigma \Delta \pm \Delta V / \Delta r q$ & $r \mathrm{rq} / \Delta \Delta \pm 9 \Delta / 9 / r$ & قند خون ناشتا قبل از مداخله \\
\hline $.1 \cdots+1$ & $-\Delta T / T V$ & $r \cdot q / \Lambda \cdot \pm q \cdot / V V Q$ & $\mid \Delta \Psi / \Delta س \pm \Delta \Psi / V V$ & قند خون ناشتا بعداز مداخله \\
\hline- & - & .1 .91 & $\cdot / \cdot v$ & سطح معنىدارى آزمون تىزوجى \\
\hline $.19 \vee 9$ & $11 / 9$ & $r \Delta N / \Gamma^{\top} \pm 1 \cdot V / \Delta Q F$ & $M F V / \cdot r \pm I r N / \cdot T^{2}$ & قند خون تصادفى قبل از مداخله \\
\hline $.1 \cdots+1$ & $1 \cdot \Delta / r$ & $m r \cdot / 1 r \pm 11 \cdot / 909$ & $r Y Y / Q T \pm \Lambda T / F \Delta$. & قند خون تصادفى بعداز مداخله \\
\hline- & - & $.1 \cdot 11$ & $.1 . .9$ & سطح معنىدارى آزمون تىزوجى \\
\hline
\end{tabular}

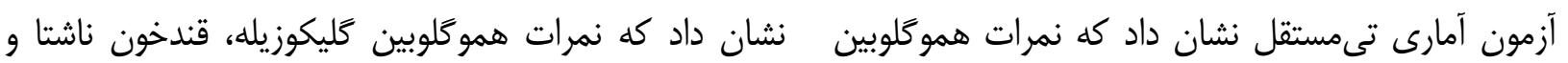

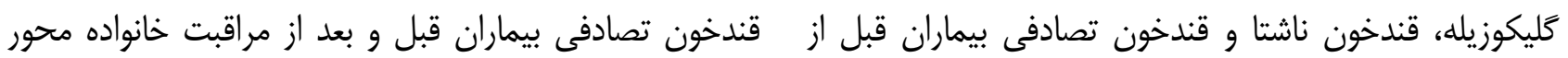

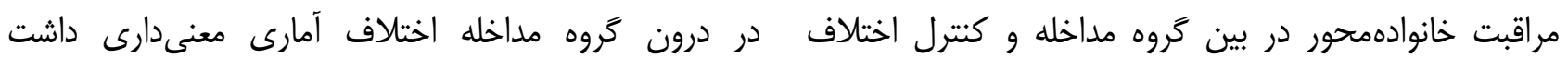

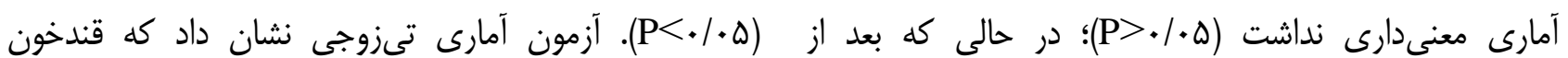

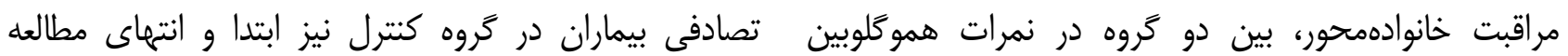

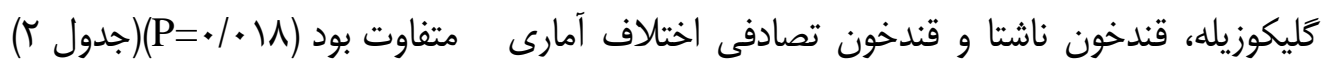

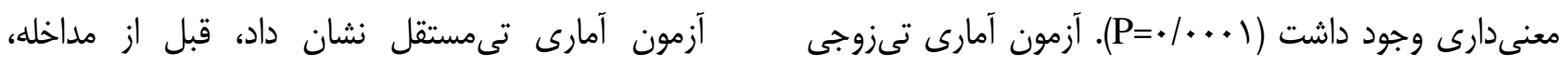


ميانگين نمرات بعد فعاليتهاى روزمره زندگى، خوديايشى قند خوديايشى قند خون، مراقبت از يا، رزيم غذايى و رزيم دارويى

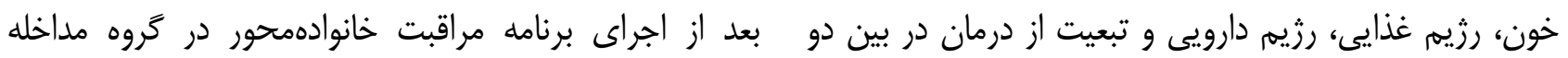

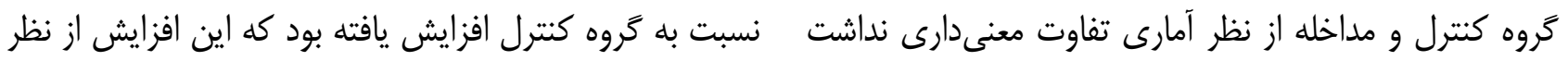

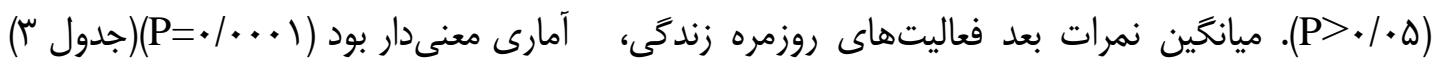

جدول بـ- مقايسه ميانكين نمرات تبعيت از درمان و ابعاد آن بين دو َّروه كنترل و مداخله قبل و بعد از اجراى مراقبت خانوادهمحور

\begin{tabular}{|c|c|c|c|c|}
\hline \multirow{2}{*}{ سطح معنى دارى } & \multirow{2}{*}{ تفاضل مداخله- كنتر ل } & تروه مداخله & تروه كنترل & \multirow{2}{*}{ 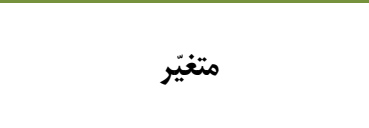 } \\
\hline & & انحراف معيار土ميانگين & انحراف معيار ذميانگين & \\
\hline ./TEA & $+\cdot 19$ & $11 / r \cdot \pm r / \omega$. & $1 \cdot / \Lambda \cdot \pm r / r$. & فعاليت هاى روزمره زندگى قبل از \\
\hline $.1 \cdots 1$ & $+\Gamma / \Delta$ & $\mid V / \Delta \Delta \pm r / \Lambda$. & $\mid r / \cdot \Delta \pm r / \varepsilon r$ & فعاليت هاى روزمره زندگى بعد از \\
\hline$\cdot \mid \& \Delta \&$ & $-\cdot / \wedge \Delta$ & 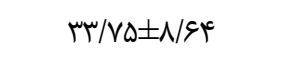 & 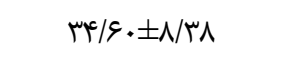 & خود پايشى قند خون قبل از مداخله \\
\hline$\cdot 1 \cdot \cdot 1$ & $+1 \cdot 1 \cdot \Delta$ & $\Delta r / ז \cdot \pm I r / r \Delta$ & $|r| r \Delta \pm 1 \cdot|q|$ & از مداخله خود پايشى قند خون بعد \\
\hline$\cdot 1 \cdot c \mathrm{~V}$ & $-r / \mathcal{L}$ & 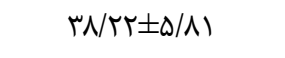 & $r \cdot / q r \pm r / v \Delta$ & مراقبت از يا قبل از مداخله \\
\hline$\cdot 1 \cdot \cdot 1$ & $+1 \cdot / 9 r \Delta$ & $\Delta F / \Delta r \pm q / \|$ & $+\varphi / s \cdot \pm V / \wedge q$ & مراقبت از يا بعداز مداخله \\
\hline$\cdot / 1 \cdot 0$ & $-Y / T V D$ & $r \cdot / I V \pm \Delta / r \Lambda$ & cr/f $\Delta \pm V / \cdot 1$ & رزيم غذايى قبل از مداخله \\
\hline$\cdot 1+\cdot 1$ & $+\& / \& \Delta$ & $\Delta r / \varepsilon \cdot \pm N / q r$ & $\Gamma \Delta /{ }^{c} \Delta \pm V / T V$ & رزيم غذايى بعداز مداخله \\
\hline.$/ 191$ & $-1 / \mathbb{R}^{\mathrm{e}} \Delta$ & $r q / \Delta \vee \pm \Delta / / r$ & $r M / \cdot \Delta \pm \Delta / \cdot r$ & رزيم دارويى قبل از مداخله \\
\hline$\cdot 1 \cdots 1$ & $+\varphi / \Delta \Delta$ & $|c| / \varepsilon \Delta \pm \psi / \cdot \Delta$ & $\Gamma \Delta / 1 \cdot \pm \Delta /{ }^{\prime}$ & رزيم دارويى بعداز مداخله \\
\hline$\cdot / \cdot \wedge \varepsilon$ & $-V / \&$ & $|\Delta Y / \Delta Y \pm| N / \Delta$ & $19 \cdot / 1 r \pm r \cdot / 9 r$ & تبعيت از درمان قبل از مداخله \\
\hline$\cdot 1 \cdot+1$ & $+H V / \& V \Delta$ & $r T / R T \pm M I / \Lambda$ & $\mid N r / \cdot \Delta \pm r N / t r$ & تبعيت از درمان بعداز مداخله \\
\hline
\end{tabular}

مطالعه حاضر نشان داد كه آموزش صحيح و متناسب

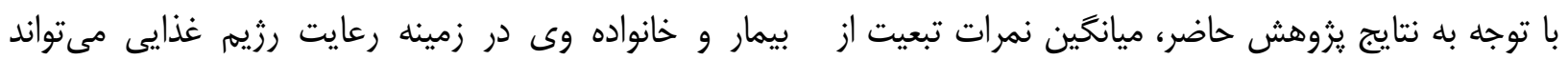

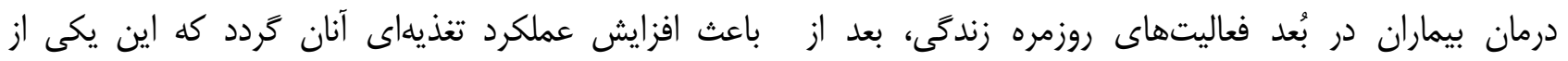

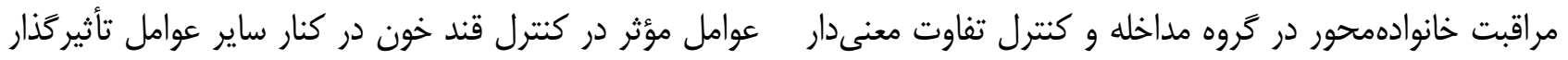

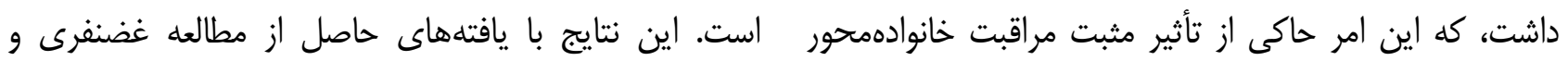

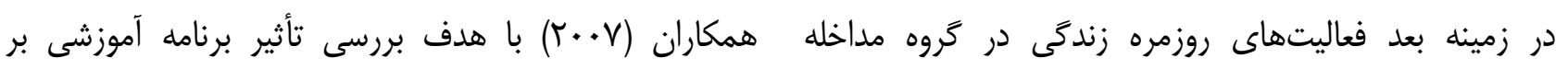

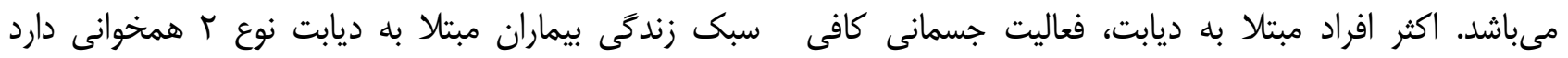

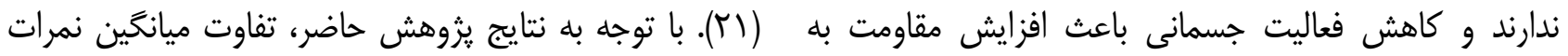

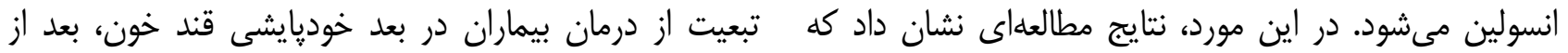

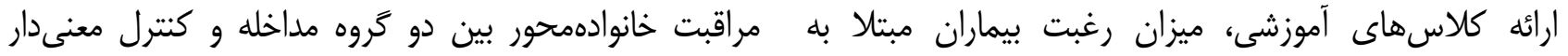

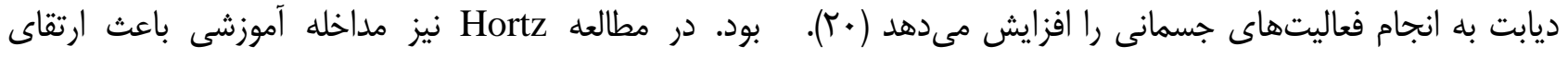

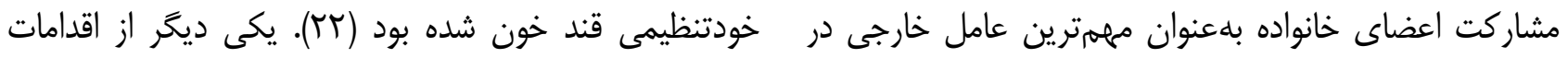

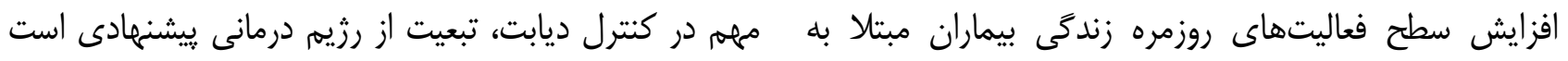

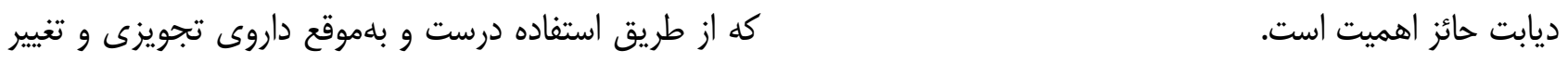


كنترل تفاوت معنىدار داشت كه اين امر مىتواند بهدليل تأثير

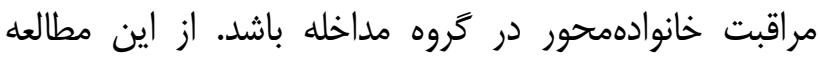

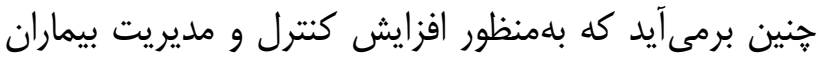

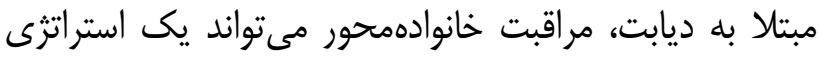

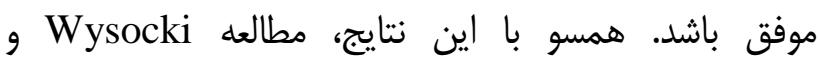

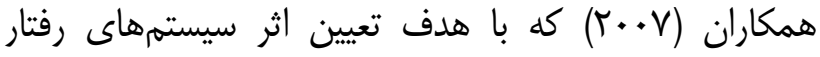
درمانى خانواده در بيمارى ديابت انجام شده بود، نشان داد كه هـ

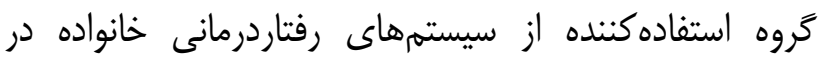
مقايسه با مراقبت معمول باعث بهبود هموكلوبين كليكوزيله

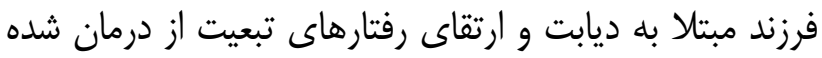

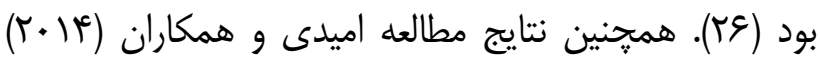

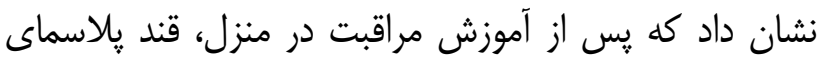

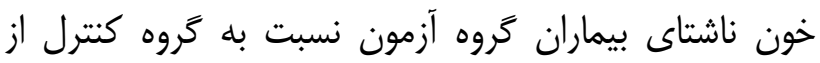

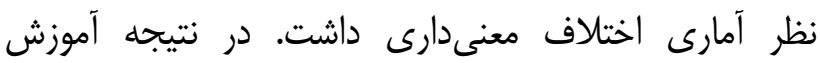

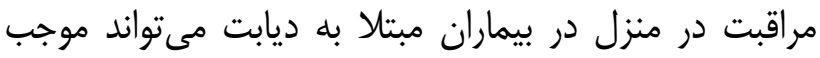

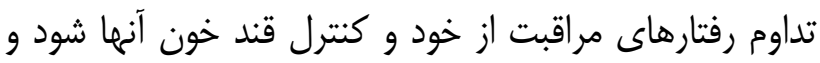

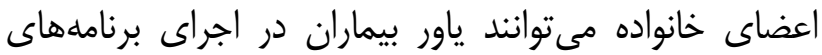

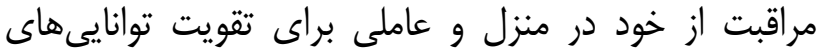

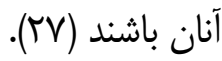

از محدوديتهاى اين يزوهش خصوصيات روحى - روانى،

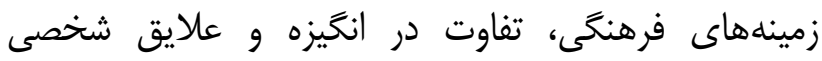

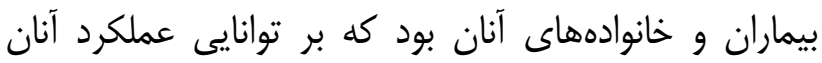

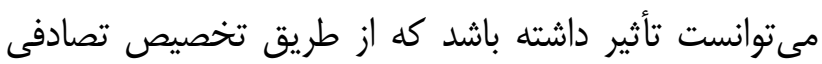

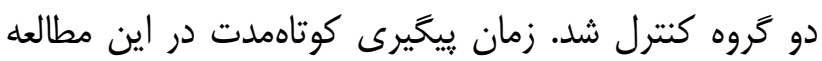

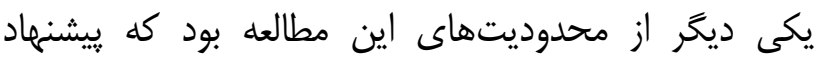

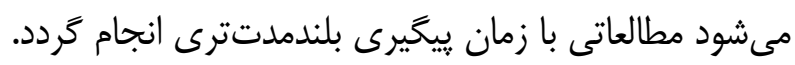

\section{نتيجل كيرى}

نتايج اين مطالعه نشان داد كه مراقبت و حمايت بيماران مبتلا به ديابت توسط خانوادههايشان باعث ارتقاى رفتارهاى

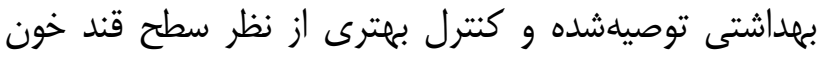

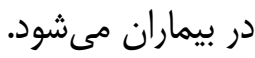

آن با نظر يزشك انجام مىشود. نتايج بهدست آمده، افزايش

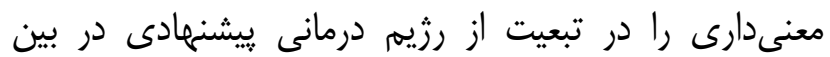

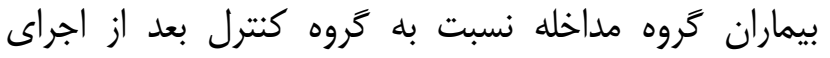

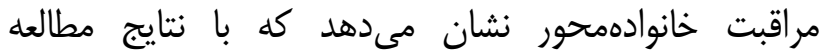

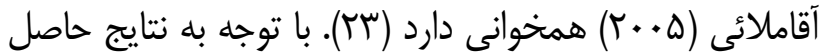

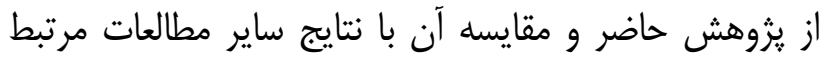
اشاره شده، به نظر مىرسد الخوى توانمندسازى خانوادهمحور مىتواند در زمينه رعايت رزيم غذايى باعث افزايش عمله سلكرد تغذيهاى بيماران گرددد.

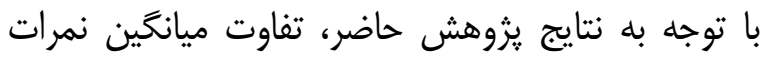

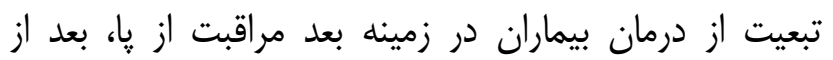

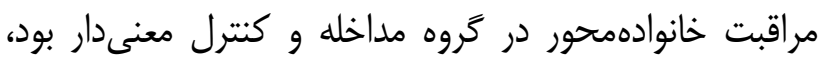
كه اين امر حاكى از تأثير مثبت مراقبت خانوادهمحور درو در زمينه

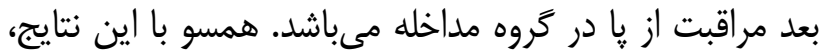
SSen آموزش بيماران مبتلا به ديابت داراى نوروياتى در مورد

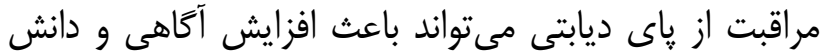
بيماران و بروز رفتارهاى خودمراقبتى از ياى ديابتى شود ( (T).

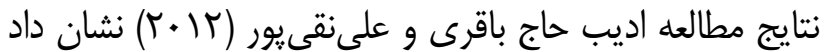

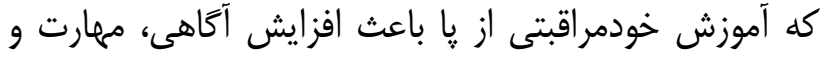

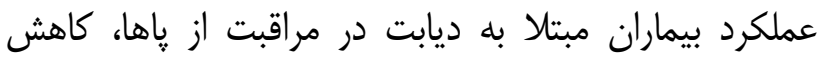

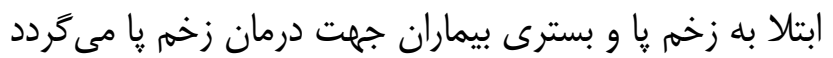
(ro)

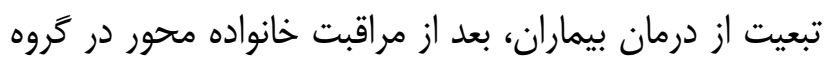

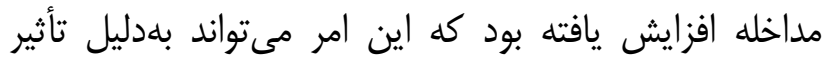

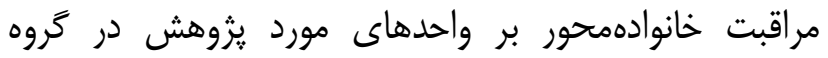

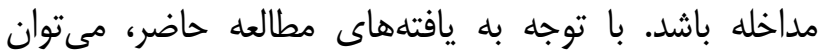

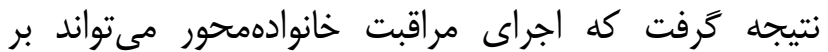
تبعيت از درمان تأثير گذار باشد. نتايج يزوهش حاضر نشان داد كه ميانخين نمرات قند خون ناشتا، تصادفى و همينطور هموكلوبين كليكوزيله

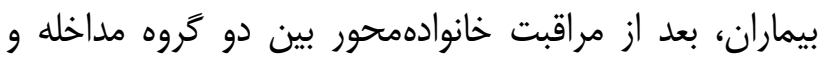




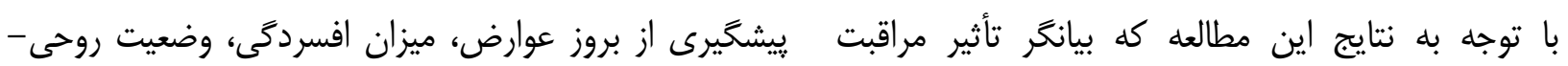

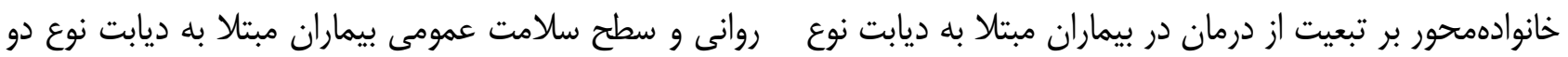

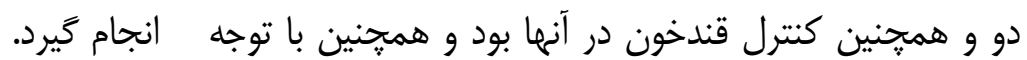

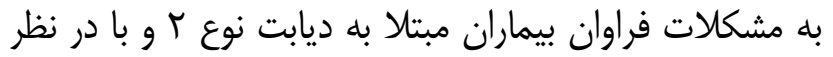

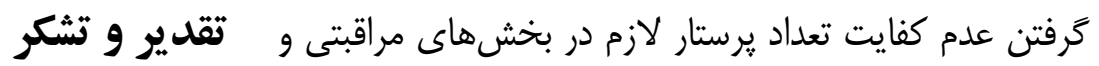
بدينوسيله از معاونت محترم يزوهشى دانشخاه علوم

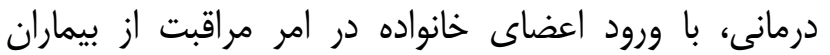

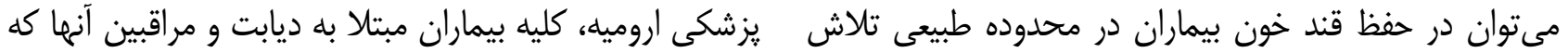

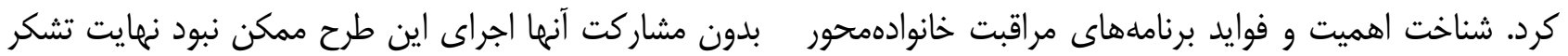

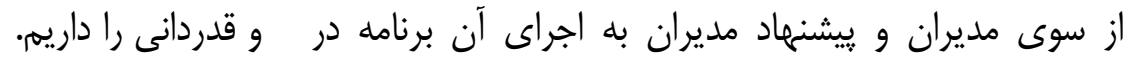

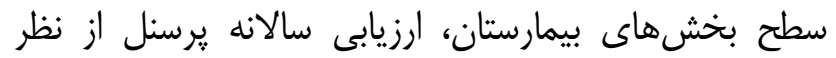
تضاد منافع: نويسندكان مقاله اعلام مى دارند كه هيج گونه تضاد

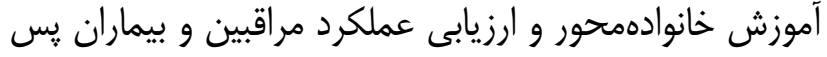
از ترخيص، مىتواند قدمى در جهت ارتقاى موارد ذكرشده منافعى در يزوهش حاضر وجود ندارد.

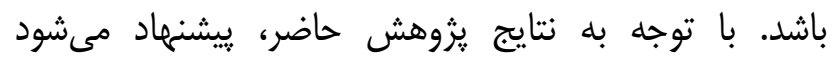

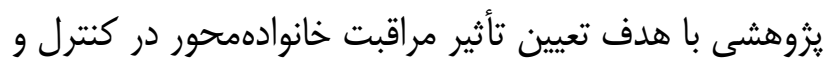

1- Association AD. Standards of Medical Care in Diabetes-2014. Diabetes Care. 2014; 37 (Suppl. 1): S14-S80D. doi: $10.2337 / \mathrm{dc} 14-\mathrm{er} 03$

2- Khawandanah J. Double or hybrid diabetes: A systematic review on disease prevalence, characteristics and risk factors. Nutr Diabetes. 2019; 9(33): 1-9. doi:10.1038/s41387-019-0101-1

3- International Diabetes Federation. IDF Diabetes Atlas, $9^{\text {th }}$ ed. Brussels, Belgium; 2019. Available at: http://www.diabetesatlas.org

4- World Health Organization. Global report on diabetes. Geneva: WHO; 2016. Available at: https://www.who.int/publications-detail/global-report-on-diabetes

5- World Health Organization. Diabetes country profiles. Geneva: WHO; 2016. Available at: https://www.who.int/diabetes/country-profiles/irn_en.pdf

6- Amini N, Bayat F, Rahimi M, Bekri G, Taheri G, Shojaeezadeh D. Effect of education on knowledge, attitude and nutritional behavior of patients with type 2 diabetes. J Health Develop. 2012; 1(4): 306-14. [Persian]

7- Tol A, Majlessi F, Mohebbi B, Rahimi Froshani A. Communication between health workers and patients: An Effective Factor in Living with Diabetes. J Hosp. 2013; 12(1): 49-56. [Persian]

8- Sotodeh Asl N, Neshat Dost H, Kalantery M, Talebi H, Khosravi A. Comparison of the effectiveness of cognitive behavioral therapy and medication on the quality of life in the patients with essential hypertension. Koomesh. 2010; 11(4): 294-301. [Persian]

9- Restrepo RD, Alvarez MT, Wittnebel LD, Sorenson H, Wettstein R, Vines DL, et al. Medication adherence issues in patients treated for COPD. Int J Chron Obstruct Pulmon Dis. 2008; 3(3): 371-84. doi:10.2147/copd.s3036

10- Gonzalez JS, McCarl LA, Wexler D DD, Cagliero E, Delahanty L, Soper TD, et al. Cognitive behavioral therapy for adherence and depression (CBT-AD) in type 2 diabetes. J Cogn Psychother. 2010; 24(4): 329-43. DOI: 10.1891/0889-8391.24.4.329 
11- Markou AL, van der Windt A, van Swieten HA, Noyez L. Changes in quality of life, physical activity, and symptomatic status one year after myocardial revascularization for stable angina. Eur J Cardiothorac Surg. 2008; 34(5): 1009-15. doi: 10.1016/j.ejcts.2008.08.003.

12- Takemura M, Mitsui K, Itotani R, Ishitoko M, Suzuki S, Matsumoto M, et al. Relationships between repeated instruction on inhalation therapy, medication adherence, and health status in chronic obstructive pulmonary disease. Int J Chron Obstruct Pulmon Dis. 2011; 6: 97-104. doi: 10.2147/COPD.S16173.

13- Naghavi S, Mehrolhassani MH, Nakhaee N, Yazdi-Feyzabadi V. Effective factors in non-compliance with therapeutic orders of specialists in outpatient clinics in Iran: a qualitative study. BMC Health Serv Res. 2019; 19(1): 413. doi: 10.1186/s12913-019-4229-4.

14- Alavi NM, Ghofranipour F, Ahmadi F, Emami A. Developing a culturally valid and reliable quality of life questionnaire for diabetes mellitus. Eastern Mediterranean Health Journal. 2007; 13(1): 177-84.

15- Clark M. Diabetes self-management education: a review of published studies. Prim Care Diabetes. 2008; 2(3): 11320. doi: 10.1016/j.pcd.2008.04.004.

16- Barrera M Jr, Toobert DJ, Angell KL, Glasgow RE, MacKinnon DP. Social support and social-ecological resources as mediators of lifestyle intervention effects for type 2 diabetes. J Health Psychol. 2006; 11(3): 483-95. DOI: $10.1177 / 1359105306063321$

17- Valizadeh F, Ghasemi SF. Medical Staff Attitude toward Parents' Participation in the Care of their Hospitalized Children. Hayat. 2008; 14(1): 69-76. [Persian]

18- Rezai Asl H, Seyyed Mazhari M, Pishgooi SAH, Alhani F. The effectiveness of "family-centered empowerment model" on the treatment adherence of patients with type II diabetes and heart disorder admitted to AJA hospitals, during year 2015. Military Caring Sciences Journal. 2017; 4(1): 58-69. [Persian]

19- Sadeghi M, Pedram Razi S, Nikbakht Nasrabadi A, Ebrahimi H, Kazemnejad A. Comparison of the impact of education based on the empowerrment model and family-center empowerrment model on knowledge and metabolic control of patients with type 2 diabetes mellitus. Journal of Nursing Education. 2013; 2(3): 18-27. [Persian]

20- Bayat F, Shojaeizadeh D, Hossaini SM, Sadeghi R, Tol A. Effectiveness of educational program on lifestyle modification among type II diabetic patients. J Health Syst Res. 2012; 8(7): 1235-1244. [Persian]

21- Ghazanfari Z, Ghofranipour F, Tavafian S, Ahmadi F, Rajab A. Lifestyle education and diabetes mellitus type 2: a non-randomized control trial. Iran J Public Health. 2007; 36(2): 68-72. [Persian]

22- Hortz BV. Evaluation of a social cognitive theory based physical activity intervention targeting leisure time physical exercise. Columbus, OH: The Ohio State University; 2005.

23- Agha MT, Eftekhar H, Mohammad K. Application of health belief model to behavior change of diabetic patients. Payesh. 2005; 4(4): 263-9. [Persian]

24- Şen HM, Şen H, Aşık M, Özkan A, Binnetoglu E, Erbağ G, et al. The importance of education in diabetic foot care of patients with diabetic neuropathy. Exp Clin Endocrinol Diabetes. 2015; 123(3): 178-81. doi: 10.1055/s-00341389981.

25- Adib-Hajbaghery M, Alinaghipoor T. The Effects of Lecture and Multimodal Methods of Teaching on Healing Rate of Diabetic Foot Ulcer and Patients' Compliance with Care Recommendations. Iran J Nurs. 2012; 25(77): 1-11. [Persian]

26- Wysocki T, Harris MA, Buckloh LM, Mertlich D, Lochrie AS, Taylor A, et al. Randomized, controlled trial of behavioral family systems therapy for diabetes: Maintenance and generalization of effects on parent-adolescent communication. Behav Ther. 2008; 39(1): 33-46. doi: 10.1016/j.beth.2007.04.001.

27- Omidi A, Miri F, Khodaveisi M, Karami M, Mohammadi N. The effect of training home care to type-2 diabetic patients on controlling blood glucose levels in patients admitted to the Diabetes Research Center of Hamadan. Avicenna J Nurs Midwifery care. 2014; 22(3): 24-32. [Persian] 